\title{
Soft retention in height fall safety devices
}

\author{
R. Irles ${ }^{1}$, J. C. Pomares ${ }^{1}$, E. G. Segovia ${ }^{1}$, M. B. Ferrer ${ }^{1}$ \\ \& E. A. Carrion ${ }^{2}$ \\ ${ }^{1}$ Civil Engineering Department, Alicante University, Spain \\ ${ }^{2}$ Building and Town Planning Department, Alicante University, Spain
}

\begin{abstract}
Height falls in construction work cause fatal or serious accidents every year. Safety devices used to avoid this are supposed to stop the falling worker by developing forces that are low enough to prevent serious injury being caused during the retention process.

In this paper three safety systems are analysed: collective protection such as safety nets (V-type) or provisory edge protection (C-class guardrails) and personal fall arrest systems (with a harness).

There are many biological and mechanical variables involved in the retention process. Maximum or minimum values are needed for kinetic energy to be absorbed; the forces against a retained worker or system deflection, respectively, are required by certain codes governing the safety systems. Other codes only establish limits for some of these variables. Code criteria about cited requirements are not homogeneous and sometimes they are even inadequate due to a lack of knowledge about the relationships and implications concerning the mechanical variables. The corresponding interaction is difficult to evaluate and requires expensive experimental studies to be carried out on instrumented real size samples.

Nevertheless, in the last decade, research on safety systems has been done on refined finite element models that can perform dynamic simulations of the impact. This paper contains important conclusions drawn from the original contributions of authors that suggest making relevant improvements to some of the corresponding codes. Comparisons of cheaper numerical predictions and real size experiments have proved that finite element models can be reliably used to analyse and design these safety devices.
\end{abstract}

Keywords: height fall, safety device, impact, energy absorption, deflection. 


\section{Introduction}

Several security devices that prevent personal height falls in construction work involve absorbing the kinetic energy produced by impacts. This is what happens with certain collective protection systems such as safety nets that are regulated in Europe by EN 1263 code [1, 2], temporary edge protection, code EN 13374 [3] and other personal protection systems, codes EN 355 [4], ANSI Z359.13 [5] and ISO 10333-2 [6].

The purpose of these devices is to prevent the person falling from seriously injuring themselves, by adequately softening the corresponding impact. Hence, the amount of kinetic energy is quoted to be much lower than in other impact events, normally by a few kJ, which is guaranteed by limiting the fall height in the device design or installation. This variable is essential in terms of kinetic energy during the retention instant. The corresponding code establishes this for each security device.

However, injuries suffered by a retained worker depend on the magnitude of the forces applied (that is to say, the accelerations, but not the velocities) during the retention instants, their direction in relation to the spine and their concentrated or distributed character. Studies on aeronautical and road vehicles [7] together with those carried out on security devices [8-10] have been made using human dummies or volunteers, which have produced reasonably safe values in each case. Maximum acceleration usually refers to that of gravity $(\boldsymbol{g})$, even when it is not in a vertical direction, as in the case of some security devices. In height fall retention devices the amount of damage done to an injured person is often only temporary (perhaps a few broken bones), but no permanent damage is done, such as fractures in the spine, damage to the nervous system, or death.

For each security system, the compatibility of the kinetic energy to be absorbed and the maximum deceleration accepted as being tolerable requires a minimum value of impact duration and system deflection, that is to say, a minimum retention path that guarantees the loss of the velocity attained with minor decelerations. This deflection depends on the design and stiffness characteristics of the security device.

Some of these maximum and minimum values are sometimes established by the corresponding codes, but this is not always the case. Moreover, the lack of information, together with the findings from recent detailed studies point to the fact that some of these values are questionable or even inadequate [11-15].

It is difficult to establish relationships between kinetic energy, body decelerations and system deflection in these impact phenomena because of nonlinearities and the sudden acceleration variation. Expensive experimental studies on full scale tests with instrumented devices and with cheaper dynamic numerical simulations can help to establish this, as demonstrated already by several authors. The use of cheaper dynamic numerical simulations for security devices is the least studied, although what has been done up to now has obtained very interesting results and design criteria, as explained hereinafter.

This paper discusses these three variables for the aforementioned security devices with the results and conclusions of original studies that highlight certain 
incoherencies and inadequate requirements in the current codes. In future reviews they should be improved to guarantee low enough decelerations and forces in fall retention processes.

\section{The kinetic energy}

Among all the cited devices, the V-type safety nets have the higher kinetic energy values. This collective safety device (fig.) is regulated in Europe by EN $1263[1,2]$ and a maximum of $7 \mathrm{~m}$ free fall is stated from a work level to the retaining net. For a worker of $100 \mathrm{~kg}$ mass, energy of $7 \mathrm{~kJ}$ is produced. The code requires the system to retain a $100 \mathrm{~kg}$ spherical ballast falling freely from this height (two successful consecutive launches are required).

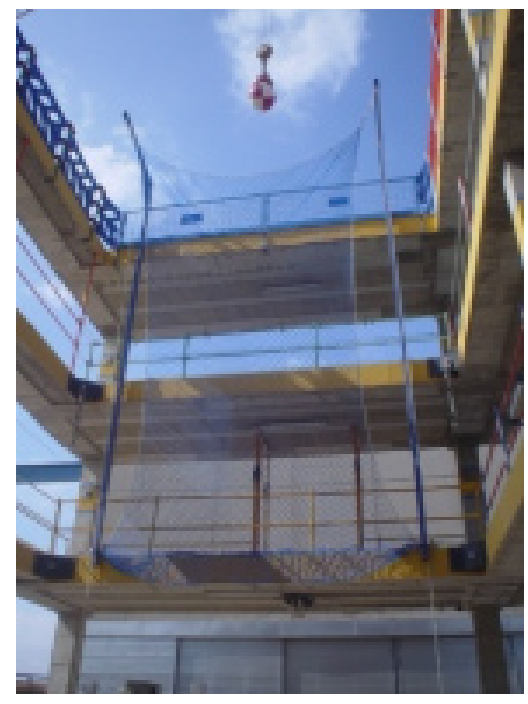

Figure 1: V-system safety net (EN 1263).

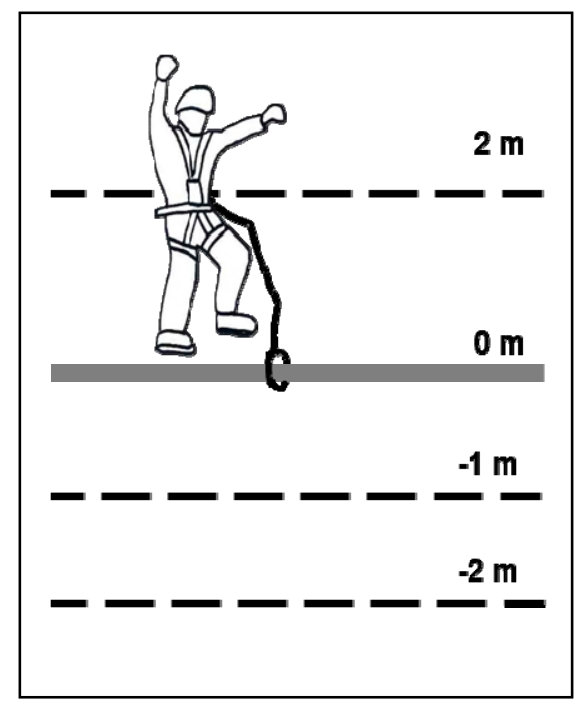

Figure 2: Personal protection system (EN 355).

Minor kinetic energy is required for a personal protection system with a harness (fig. 2). $4 \mathrm{~kJ}$ due to a free fall of a $100 \mathrm{~kg}$ mass through a $4 \mathrm{~m}$ height fall is required by EN 355 [4] and ISO 10333-2 (2000) [6] (type 2 systems); other codes establish similar values or lower ones for other systems, as summarised in table 1 together with other requirements for specified tests.

The lowest values required among those produced by the safety systems under analysis are for the temporary edge protection systems (fig. 3). This collective safety protection is regulated by EN 13374 (2013) [3] that establishes several types depending on the surface slope (fig. 4). For the more severe type $\mathrm{C}$ the code specifies a kinetic energy of $2.2 \mathrm{~kJ}$, although the required test produces a higher energy value (up to nearly $3.2 \mathrm{~kJ}$ ); whose precise calculation is difficult 
because in this case the $75 \mathrm{~kg}$ ballast fall is not free, but rolls or slides on the working surface. A lower value of $1.1 \mathrm{~kJ}$ is specified for type B for minor working surface slopes or heights; with only static requirements for type A (quasi horizontal surface).

Table 1: Code requirements for fall height safety devices.

\begin{tabular}{|l|l|l|l|l|l|l|}
\hline \multicolumn{1}{|c|}{ CODE } & $\begin{array}{l}\text { Fall } \\
\text { height } \\
(\mathrm{m})\end{array}$ & $\begin{array}{l}\text { Falling } \\
\text { mass } \\
(\mathrm{kg})\end{array}$ & $\begin{array}{l}\text { Kinetic } \\
\text { energy } \\
(\mathrm{kj})\end{array}$ & $\begin{array}{l}\text { Max. } \\
\text { force } \\
(\mathrm{kn})\end{array}$ & $\begin{array}{l}\text { Max. } \\
\text { accel } \\
(\mathrm{g})\end{array}$ & $\begin{array}{l}\text { Min. } \\
\text { deflec } \\
(\mathrm{m})\end{array}$ \\
\hline EN355 & 4.00 & 100 & $4.0 *$ & 6 & $5.00^{*}$ & 1.75 \\
\hline ANSI Z359.13 & 1.80 & 128 & $2.3 *$ & 8 & $5.25^{*}$ & 1.22 \\
\hline ANSI Z359.13 & 3.60 & 128 & $4.6 *$ & 8 & $5.25^{*}$ & 1.52 \\
\hline ISO 10333-2 & 1.80 & 100 & $1.8 *$ & 4 & $3.00^{*}$ & 1.20 \\
\hline ISO 10333-2 & 4.00 & 100 & $4.0 *$ & 6 & $5.00^{*}$ & 1.75 \\
\hline $\begin{array}{l}\text { EN1263 } \\
\text { (V-type) }\end{array}$ & 7.00 & 100 & $7.0 *$ & - & - & - \\
\hline $\begin{array}{l}\text { EN13374 } \\
\text { (C-class)** }\end{array}$ & & & 2.2 & & & \\
\hline $\begin{array}{l}\text { EN13374 } \\
\text { (C-class)*** }\end{array}$ & $4.33 *$ & 75 & $3.2 *$ & - & - & 0.20 \\
\hline $\begin{array}{l}\text { EN13374 } \\
\text { (B-class) }\end{array}$ & $2.20 *$ & 50 & 1.1 & - & - & 0.10 \\
\hline
\end{tabular}

*calculated by authors; $* *$ nominal requirement; $* * *$ required test.

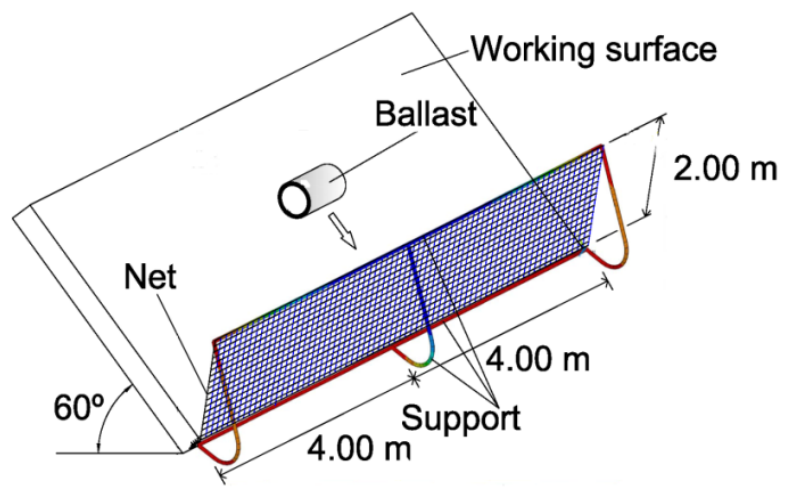

Figure 3: Temporary edge protection systems (EN 13374). 


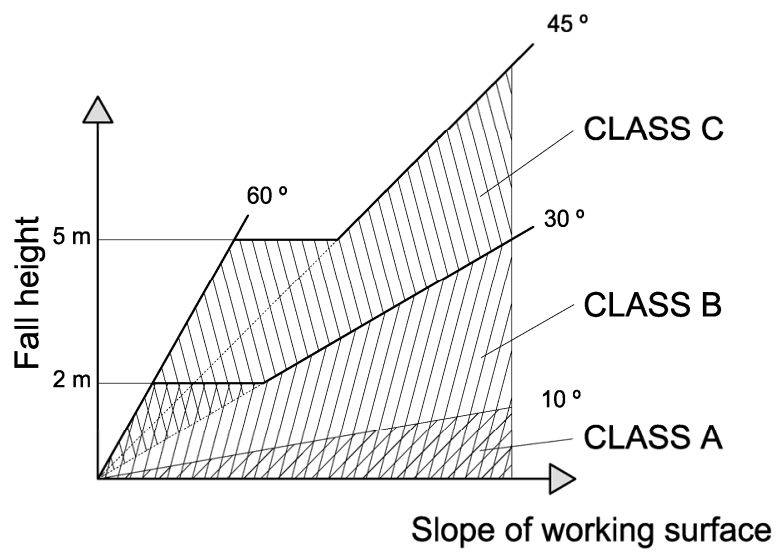

Figure 4: Temporary edge protection classes by EN 13374.

\section{The maximum forces and decelerations}

\subsection{General requirements}

The maximum forces (or decelerations) during the retention process should be fixed with regard to the injury suffered by the falling person. These maximum values depend on multiple factors, the most relevant being:

-concentrated or distributed character of forces

-direction of forces with regard to the spine of the human body

-duration of the acceleration applied

Aerospatial navigation studies, in which the individual is subjected to considerable acceleration and distributed forces, have been organised for decades with volunteers being seated or lying down in a chair. These studies [7] conclude that a person can resist considerable distributed forces and accelerations (table 2) without suffering any serious injury. However, in this case, the time in which the acceleration lasts (a few seconds) is much greater than the duration for the analyzed safety systems (a few deciseconds) and some of the injures are caused by insufficient brain irrigation.

For personal arrest systems, Sulowski [8-10] organised studies and experiments with dummies or volunteers and concluded that maximum forces which do not seriously injure the falling person should not exceed values that are much lower (table 2).

Unfortunately, similar results have not been obtained for the V-type safety nets or the C-class temporary guardrails. However, net systems distribute the forces applied to the body in an intermediate situation between the aerospatial seats and the harness systems. Various theoretical studies carried out on safety nets [16] took into consideration the intermediate values for maximum 
acceleration, nearly $16 \mathrm{~g}$, that were included in the R305 old French rule [17], although this could be excessive for certain fall positions in the author's opinion.

Table 2: Maximum suitable forces or accelerations.

\begin{tabular}{|l|l|l|l|l|l|}
\hline Event & Ener (kj) & Ref. & Case & Accel $(\mathrm{g})$ & Force $(\mathrm{kn})$ \\
\hline $\begin{array}{l}\text { Aircraft } \\
\text { flight }\end{array}$ & - & Voshell & Parallel to spine & 10 & $10^{*}$ \\
\cline { 3 - 6 } & & $\begin{array}{l}\text { Perpendicular to } \\
\text { spine }\end{array}$ & 20 & $20^{*}$ \\
\hline $\begin{array}{l}\text { Personal } \\
\text { harness } \\
\text { system }\end{array}$ & 4 & Sulowski & Parallel to spine & $5^{*}$ & 6 \\
\cline { 3 - 6 } & & & Perp. lateral & $3^{*}$ & 4 \\
\cline { 3 - 6 } $\begin{array}{l}\text { V-type } \\
\text { safety net }\end{array}$ & 7 & Perp. frontal & $1.5^{*}$ & 2.5 \\
\hline & & authors & - & $16^{*}$ & 17 \\
\hline $\begin{array}{l}\text { C-class } \\
\text { guardrail }\end{array}$ & 3.2 & authors & - & $9-11$ & $10-12$ \\
\hline
\end{tabular}

*equivalence for a $100 \mathrm{~kg}$ mass.

\subsection{Code requirements}

In the systems analysed, only current codes for personal arrest systems produce maximum values for the impact forces. They are summarised in table 1 with the corresponding mass, height fall, deceleration values and other data discussed hereinafter.

\subsection{Measurement}

Dynamic dynamometers, strain gages, accelerometers and high speed cameras have been used in experiments with volunteers or with a ballast $[14,15]$. Figure 5 shows the modulus of acceleration obtained in an experimental study of the C-type guardrail.

Due to the high cost and the difficulties found when carrying out experimental tests, numerical simulations provide for a few expensive measurements of many variables in the dynamic retention process. In recent years we have developed several ANSYS [18] numerical models $[12,13]$ to study these safety devices in which many unknown values produced up until that moment have been measured. Figure 6 shows numerical results for the experimental results in figure 5 , whose maximum values are close to $12 \mathrm{~g}$, which means that they are in line with each other. C-class systems currently used with straight supports have an additional problem that is recognized by their own code, which happens when the impact goes directly against the support. In this case, the concentrated developed forces are tremendous; they might kill the injured person or cause irreversible damage to them. Some of authors have developed $[14,15]$ an ergonomic system without straight supports to avoid direct impact on this edge protection system. 


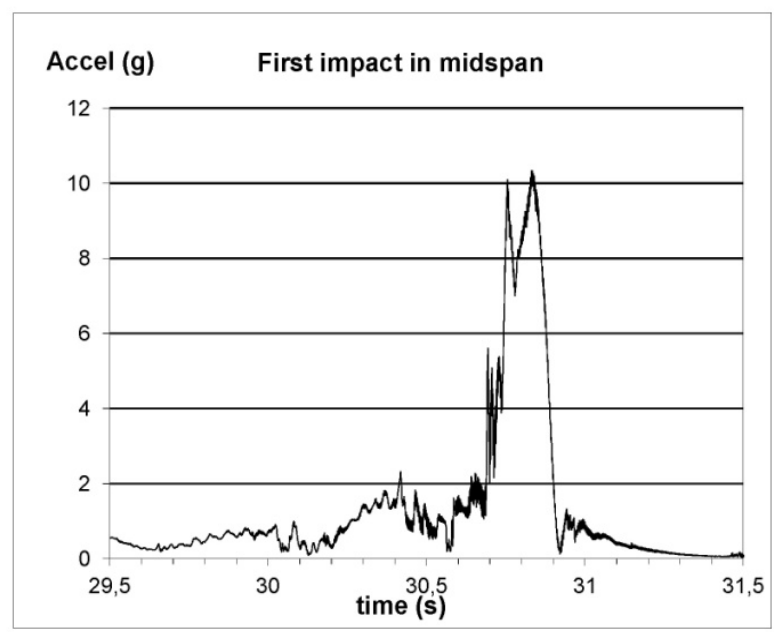

Figure 5: Acceleration in the $\mathrm{C}$ type guardrail from an accelerometer.

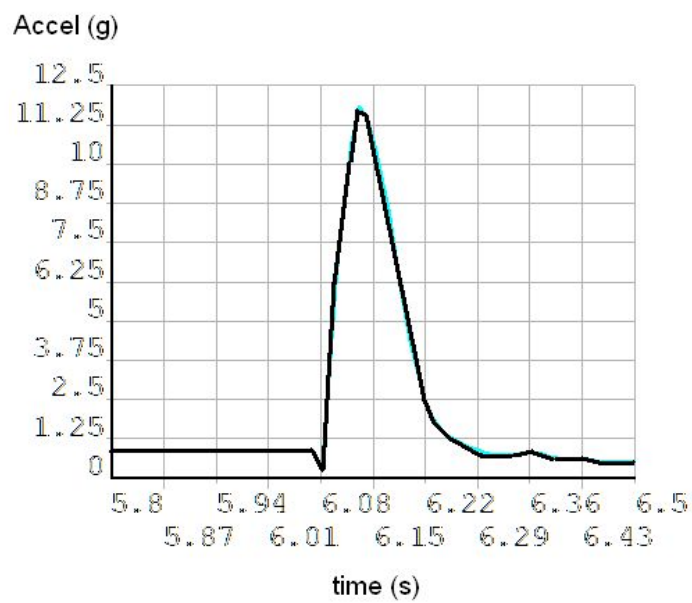

Figure 6: Acceleration in a C-type guardrail from a numerical model.

Moreover, the authors highlight satisfactory behaviour in various real accidents involving falls on V-type safety nets in Spain and although data on accelerations was not obtained they are numerically evaluated to be around $6 \mathrm{~g}$ (fig. 7) [19]. 


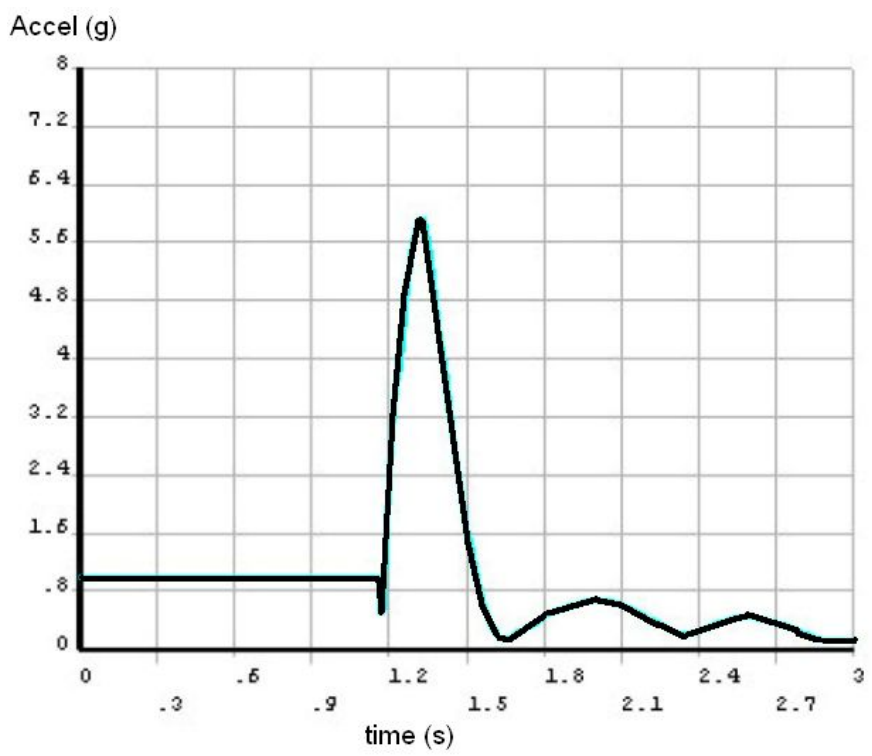

Figure 7: Acceleration in a V-type safety net from a numerical model.

Figure 8 shows acceleration obtained by a numerical model for a personal protection system with a harness. It concerns a $4 \mathrm{~m}$ height fall of a $100 \mathrm{~kg}$ mass with a $2 \mathrm{~m}$ length rope of $\varnothing 10 \mathrm{~mm}$ (from a current study being carried out by the authors).

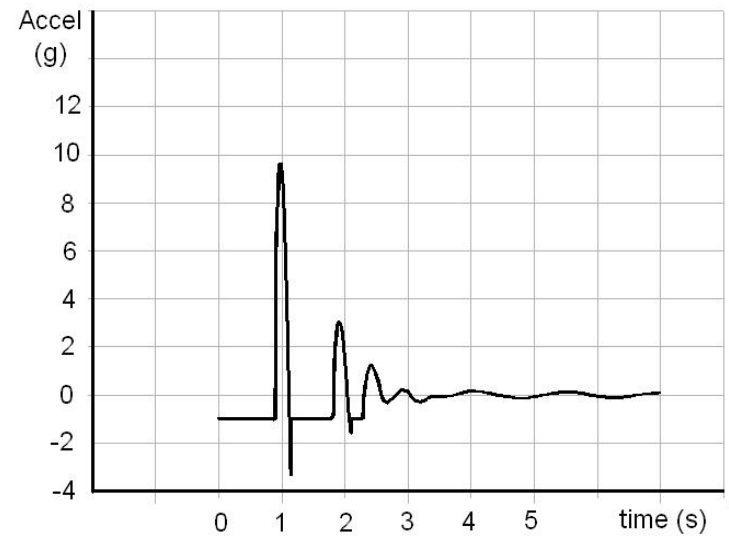

Figure 8: Acceleration in a harness system from a numerical model.

It is much cheaper to analyze each variable in the problem using numerical models that are well-calibrated from a few real size experiments and it can be very useful to design a safety device that has to absorb an amount of kinetic 
energy if the accelerations and forces that cause injuries are going to be limited. In this sense, numerical models should also be considered as being useful tools by the safety device standardization working groups and committees.

\section{The minimum system deflection}

\subsection{General requirements}

Acceleration $\boldsymbol{a}(\boldsymbol{t})$ in impacts is variable in time, as shown in figures 5 to 8 . Initial velocity $\boldsymbol{v}_{\boldsymbol{o}}$ when instant retention begins (contact with net, tension in the cord) can be calculated for a given mass $\boldsymbol{m}$ according to the amount of energy to be absorbed, in its kinetic expression

$$
E_{K}=\frac{1}{2} m v_{0}^{2} \rightarrow v_{0}=\sqrt{\frac{2 E_{k}}{m}}
$$

Given the initial velocity that disappears during the impact, the following is required

$$
v\left(t_{i}\right)=v_{0}+\int_{0}^{t_{i}} a(t) d t=0 \rightarrow t_{i}=\ldots
$$

and to limit a maximum value for $\boldsymbol{a}(\boldsymbol{t})$ that produces enough time $\boldsymbol{t}_{\boldsymbol{i}}$ (a few deciseconds). Then the retention path or maximum system deflection

$$
s\left(t_{i}\right)=\int_{0}^{t_{i}} v(t) d t=\int_{0}^{t_{i}}\left[v_{0}+\int_{0}^{t} a(t) d t\right] d t
$$

should be long enough too.

\subsection{Code requirements}

Some safety codes prescribe a minimum value for maximum deflection of the system during the retention process (table 1) that should be coherent with maximum developed forces.

\subsection{Measurement}

For real size experiments on these safety devices, maximum deflection can be measured by means of a high speed camera [14]. Alternatively it can be predicted using numerical models $[12,13]$. Table 3 shows the deflection value in each safety system, along with the corresponding energies and maximum accelerations (and forces), as predicted by numerical models. This should agree with deflections for (a) and accelerations and deflections for (b) and (c) that are also measured experimentally $[11,14,15]$.

Note that the values of maximum accelerations and deflections are within the range of reasonable values, except in the case of the type $\mathrm{C}$ provisory guardrails that have $0.200 \mathrm{~m}$ minimum deflection (c). EN 13374 does not stipulate any 
requirements when it comes to maximum forces or accelerations, but for the minimum required value to the maximum deflection $(200 \mathrm{~mm})$ accelerations can reach values of nearly $40 \mathrm{~g}$, developing unacceptable forces, which has also been demonstrated by experimental studies [14].

Table 3: Deflection and acceleration from numerical models.

\begin{tabular}{|c|c|c|c|c|c|}
\hline $\begin{array}{l}\text { Safety } \\
\text { system }\end{array}$ & $\begin{array}{l}\text { System } \\
\text { charact. }\end{array}$ & $\begin{array}{c}\text { Energy } \\
(\mathrm{kj})\end{array}$ & $\begin{array}{l}\text { Max. } \\
\text { Accel. } \\
(\mathrm{g})\end{array}$ & $\begin{array}{c}\text { Max. } \\
\text { Force } \\
(\mathrm{kn})\end{array}$ & $\begin{array}{l}\text { Max. } \\
\text { Defl. } \\
(\mathrm{m})\end{array}$ \\
\hline $\begin{array}{l}\text { V-type } \\
\text { safety net }\end{array}$ & $\begin{array}{l}\text { (a) steel frame } \\
60.60 .3 \\
\text { Safety Net (*). }\end{array}$ & 7 & 6 & 7 & 1.400 \\
\hline \multirow[t]{2}{*}{$\begin{array}{l}\text { C-class } \\
\text { provisory } \\
\text { Guardrail }\end{array}$} & $\begin{array}{l}\text { (b) steel frame } \\
\varnothing 48.3 \\
\text { ergonomic } \\
\text { supports } \\
\text { Safety net }(*)\end{array}$ & 3.2 & 11.5 & 11.5 & 0.850 \\
\hline & $\begin{array}{l}\text { (c) reinforced } \\
\text { system } \\
\text { to reduce } \\
\text { deflection }\end{array}$ & 3.2 & 35 & 36 & 0.200 \\
\hline \multirow[t]{2}{*}{$\begin{array}{l}\text { Personal } \\
\text { fall } \\
\text { arrest }\end{array}$} & $\begin{array}{l}\text { (d) } 4 \mathrm{~m} \text { fall } \\
\text { height } \\
2 \mathrm{~m} \text { Rope }(* *) \\
\text { without } \\
\text { energy } \\
\text { absorber }\end{array}$ & 4 & 10 & 11 & 0.440 \\
\hline & $\begin{array}{l}\text { (e) } 2 \mathrm{~m} \text { fall } \\
\text { height } \\
2 \mathrm{~m} \text { Rope }(* *) \\
\text { without } \\
\text { energy } \\
\text { absorber }\end{array}$ & 2 & 6.3 & 7.2 & 0.370 \\
\hline
\end{tabular}

(*) Safety net: high tenacity polyamide, 100x100 mm (knot to knot) with perimeter rope.

(**) Rope: $\varnothing 10 \mathrm{~mm}$ and density $0.07 \mathrm{~kg} / \mathrm{m}$.

Reasonable values for maximum accelerations in this system require a much bigger deflection as shown in the table on the more flexible system (b). It should be noted that the energy to be absorbed in the provisional C-class guardrails is similar to that of the personal arrest systems with a harness, with a minimum deflection requirement that is higher than $1000 \mathrm{~mm}$ in all cases.

Preliminary results (d) and (e) of numerical models for personal arrest systems suggest that usual ropes without an energy absorber device could also be too stiff and could produce forces that are too high, thus the plastic behaviour of 
this device is essential to attain enough deflection to generate admissible maximum forces.

\section{Conclusions}

- Safety devices to prevent height falls in construction work should be able to guarantee that a certain value of accelerations and forces is not exceeded during a retention event, and is low enough not to cause serious injury to the falling worker.

- Forces that can cause serious injury vary in an appreciable range, depending on their direction with regard to the spine and their concentrated or distributed character in an impact. This is associated with each safety system design. Fall arrest with a harness produces more concentrated forces. Net systems produce more distributed forces, as long as they can guarantee that direct impact with hard supports is avoided, which is possible when a properly designed support frame is used.

- These accelerations and forces are mechanically related to how long the impact lasts, to the path when stopping (or maximum system deflection) and to the mass of the falling worker (plus equipment). All these variables, except the latter, depend on the global stiffness of the corresponding safety device, either elastic or plastic, whenever appropriate.

- In comparison with a few real size experiments, numerical models with a finite elements technique have proved to successfully simulate this kind of impact. Multiple variables involved, which are difficult to assess, can also be measured and this favours progress in the analysis of current safety systems and the research into the design of new ones.

- Safety code requirements to prevent fall heights show a considerable dispersion for maximum forces and deflections during the retention process. Some codes do not include explicit requirements for one or either of them. Code requirements for personal harness systems appear to be the most coherent among the systems analyzed. A special mention should be made to EN 13374, whose minimum required deflection $(200 \mathrm{~mm})$ has produced accelerations and forces that are too high.

- The next review of EN 13374 should consider increasing the minimum required deflection. Numerical and experimental studies prove that a C-class provisory guardrail with a net showing a maximum deflection of 800 to 900 $\mathrm{mm}$ produces reasonable forces and accelerations.

\section{References}

[1] ECS. EN 1263. Security Nets. Part 1: Security requirements, Test methods, 2002.

[2] ECS. EN 1263. Security Nets. Part 2: Security requirements for installing Security nets, 2004.

[3] ECS. EN 13374. Temporary Edge Protection Systems Product Specification, test methods, 2013. 
[4] ECS. EN 355. Personal protective equipment against falls from a height. Energy absorbers, 2002.

[5] ASSE. ANSI/ASSE Z359.13. Personal Energy Absorbers and Energy Absorbing Lanyards, 2009.

[6] ISO 10333-2. Personal fall-arrest systems. Part 2: Lanyards and energy absorbers. 2000.

[7] González, A.; Ríos, F. Effects of Positive Accelerations on the Human Organism. Aerospatiale and Environmental Medicine, Vol. 3 (5): 222-231, 2002.

[8] Sulowski, Andrew C. How good is the $8 \mathrm{kN}$ Maximum Arrest Force limit in industrial Fall Arrest System? Seattle 2006.

[9] Sulowski, A.C. et al. "Fundamentals of Fall Protection" International Society Fall Protection, pp. 405, Toronto 1991.

[10] Brinkley, J. W.; Sulowski, A.C. "Measurement of Maximum Arrest Force in Performance Test of Fall Protection Equipment". Journal of Testing and Evaluation: JTEVA. Vol. 18, N.2, pages 123-127, 1990.

[11] Irles Más, R; González Sánchez, A.; Segovia Eulogio, E.; Maciá Mateu, A. "Vertical Security Nets in Building Construction I". Informes de la Construcción, volume 53, N.477, 21-29, 2002.

[12] Segovia Eulogio, E.; Irles Más, R.; González Sánchez, A., Maciá Mateu, A.; Pomares Torres, J. C. "Vertical Security nets in building construction II". Informes de la Construcción, volume 59, nº 505, 37-51, 2007.

[13] Pomares, J.C; Segovia, E.G.; Irles, R. Personal protection handrails for strong impacts. $4^{\text {th }}$ Int. Confer. on Safety and Security Engineering, SAFE 2011. Antwerp (Belgium), July 2011.

[14] Pomares, J.C.; Ferrer, B.; Más, D.; Lozano, C.; Bresó, S.; Irles, R. Experimental measure of impact in temporary handrails. $12^{\text {th }}$ Int. Confer. on Structures Under Shock and Impact, SUSI 2012, Kos (Greece), September 2012.

[15] Ferrer, B.; Pomares, J.C.; Irles, R., Espinosa, J, Más, D. High speed image techniques for construction safety net monitoring in outdoor conditions. Conferences on optics, photonics and digital technologies for multimedia applications. SPIE. Brussels (Belgium), April 2012.

[16] Paureau, J.: "Filets carrés de sécurité en grandes nappes en polyamide 6. Performances. Règles de pose". Institut Nacional de Recherche et Sécurité, Vandoeuvre-les-Nacy (France), (In French), 1987.

[17] Recommandation R305. Comité Technique National des Industries du Bâtiment et des Travaux Publics. Travail et Sécurité, n6, 1988.

[18] ANSYS Theory reference 8.1, Ansys Inc. 2003.

[19] Segovia Eulogio, E.G., Doctoral thesis: Criteria for the design of fall arrest systems used in construction and subjected to impact. September 2004. 